\title{
Solusi Analitik Persamaan Schrodinger Terdedeformasi- $q$ dengan Potensial Kratzer dalam Sistem Koordinat Bispherical Menggunakan Metode SUSYQM
}

\author{
Dedy A Bilaut ${ }^{1}$, C Cari $^{2}$, A Suparmi ${ }^{2}$, Miftahul Ma'arif ${ }^{1}$ \\ 1 Program Studi S2 Ilmu Fisika, Pascasarjana Universitas Sebelas Maret, \\ Jl. Ir. Sutami no 36 Kentingan Surakarta \\ 2 Program Studi Fisika, Fakultas MIPA Universitas Sebelas Maret, \\ Jl. Ir. Sutami no 36 Kentingan Surakarta \\ Email: bilautdedy@gmail.com
}

\begin{abstract}
The analytical solution of the Schrodinger equation affected by Kratzer potential in Bispherical coordinate system was derived. The separable method was applied to reducing the Schrodinger equation which depends on $\mu, \theta, \phi$ into three one-dimensional Schrodinger equations. The Schrodinger equations as the function of $\mu$ with and without q-deformed were solved using the SUSY QM method. The solutions were eigenvalue and eigenfunction of $q$-deformed Schrodinger equation and eigenvalue end eigenfunction of Schrodinger equation with and without q-deformed in Bispherical coordinate system. The energy of the Schrodinger equation with q-deformed equals to the Energy of Schrodinger without q-deformed since the q parameter becomes to zero.
\end{abstract}

Keywords: Schrodinger equation, eigen solution, Kratzer potential, Bispherical coordinate, SUSY QM

\begin{abstract}
Abstrak: Solusi analitik dari Persamaan Schrodinger yang dipengaruhi Potensial Kratzer dalam koordinat Bispherical telah berhasil diturunkan. Metode pemisahan variabel digunakan untuk mereduksi persamaan Schrodinger yang bergantung pada $\mu, \theta, \phi$ menjadi tiga persamaan Schrodinger satu dimensi. Persamaan Schrodinger fungsi $\mu$ terdeformasi- $q$ dan tidak terdeformasi- $q$ diselesaikan menggunakan metode SUSY QM. Solusi yang berhasil didapatkan adalah nilai eigen dan fungsi eigen persamaan Schrodinger, masing-masing untuk sistem terdeformasi- $q$ dan yang tidak terdeformasi- $q$ dalam koordinat Bispherical. Energi dari persamaan Schrodinger terdeformasi- $q$ sama dengan energi dari persamaan Schrodinger yang tidak terdeformasi- $q$ ketika $q$ sama dengan nol.
\end{abstract}

Kata kunci: Persamaan Schrodinger, Solusi eigen, Potensial Kratzer, Koordinat Bispherical, SUSY QM

\section{PENDAhUluan}

Persamaan Schrodinger memiliki daya tarik tersendiri bagi para fisikawan terkhususnya di bidang teori kuantum karena memiliki banyak manfaat dalam mempelajari fisika zat padat, kimia kuantum, teori informasi dan scattering theory. Persamaan energi dan fungsi gelombang merupakan solusi dari persamaan Schrodinger yang didalamnya terkandung banyak informasi penting dari suatu sistem kuantum (Awoga \& Ikot, 2012). Ketika nilai eigen dan fungsi gelombang ini diperoleh maka selanjutnya sifat-sifat suatu sistem kuantum seperti sifat termodinamika, optikal dan informasi entropi dapat diturunkan (Berkdemir, Berkdemir, \& Han, 2006; Ikhdair \& Sever, 2007).

Beberapa penelitian terdahulu telah dilakukan untuk menemukan solusi analitik dari persamaan Schrodinger yang dipengaruhi beberapa potensial penting seperti potensial Scarf (Alvarez-Cas, Tillo, \& Kirchbach, 2007), potensial Eckart (Taskin \& Kocakt, 2010), dan potensial Hellmann-generalized Morse (Ebomwonyi, Onate, Onyeaju, \& Ikot, 2017). 
Penelitian-penelitian sebelumnya membuktikan bahwa penelitian dengan melibatkan potensialpotensial ini masih menjadi topik penting yang perlu dikembangkan karena setiap potensial mempunyai keunikan dan fungsinya masing-masing dalam dunia kuantum. Potensial Scarf digunakan dalam mempelajari medan elektomagnetik dan teori partikel fisika zat padat potensial (Alvarez-Cas et al., 2007), Potensial Poschl-Teller digunakan untuk mempelajari teori informasi kuantum (Atre, Kumar, Kumar, \& Panigrahi, 2004) dan partikel-partikel terdeformasi (Hassanabadi, Ikot, \& Zarrinkamar, 2014), serta berbagai potensial bentuk cincin dan cincin ganda yang dipakai untuk mempelajari berbagai macam molekul organik (Cheng \& Dai, 2007).

Potensial Kratzer digunakan untuk menganalisis vibrasi antar nuklir dari molekul-molekul diatomik. Baru-baru ini potensial Kratzer dipakai untuk mengamati sifat optik linear dan nonlinear dari molekul-molekul diatomik seperti $\mathrm{CO}, \mathrm{NO}, \mathrm{O}_{2}$, and $\mathrm{I}_{2}$ (Ikot et al., 2020). Secara matematis, potensial Kratzer dapat dituliskan sebagai berikut

$$
\mathrm{K} U(\mu)=\frac{D_{e} r_{0}}{\mu^{2}}-\frac{2 D_{e} r_{0}}{\mu}
$$

dengan $D_{e}$ adalah energi disosiasi, dan $r_{0}$ adalah jarak antar nuklir dalam kedaan setimbang. Potensial yang dipakai untu menganalisis molekul-molekul diatomik ini juga dapat dimodifikasi menjadi potensial tipe cincin dan cincin ganda (Ring-Shaped dan Double RingShaped) yang bisa digunakan untuk mengamati molekul organik (Durmus \& Yasuk, 2007).

Koordinat Bispherical $(\mu, \theta, \phi)$ adalah salah satu dari koordinat kurvalinear seperti koordinat Toroidal yang dimodifikasi dari dua koordinat bipolar dimana kedua titik fokusnya terpisah oleh jarak $a$ (Anthonys, 2018; Moon \& Spencer, 1971). Kordinat-koordinat seperti ini banyak diapakai ketika mengamati teknologi nanotube, serta medan listrik dan medan magnet (Belov, Dobrokhotov, \& Tudorovskii, 2004; Krejčiŕík \& Raymond, 2014). Dalam kajian teoritik fisika partikel, koordinat ini juga dipakai untuk mengamati kebiasaan partikel nonrelativistik dalam sistem kurvalinear (Ferrari \& Cuoghi, 2008). Solusi dari persamaan Schrodinger dengan potensial Yukawa dalam suatu sistem koordinat Toroidal (Faniandari, Suparmi, \& Cari, 2020), Solusi fungsi eigen dari persamaan Schrodinger suatu partikel yang bergerak pada torus (Encinosa \& Etemadi, 2002) adalah contoh penelitian terdahulu yang mendukung penelitian ini.

Terdapat beberapa metode yang dipakai untuk mendapatkan solusi analitik (nilai eigen dan fungsi eigen) dari persamaan gelombang non-relativistik dan juga relativistik. Metode Nikiforov-Uvarov (NU) (Karayer, 2019), metode Asymptotic Iteration method (AIM) (Ikot et al., 2020), metode faktorisasi (Mir-Kasimov, 2013), metode Time Step (Zhang, Liang, \& Meng, 2009), pendekatan algebra (Shishan, Dong, Bahlouli, \& Bezerra, 2011), dan metode Supersymmetric Quantum Mechanics (SUSY QM) adalah beberapa metode yang sering dipakai untuk menyelesaikan persamaan Schrodinger. SUSY QM adalah metode yang diusulkan oleh Witten dan terkenal dengan konsep shape invariance. Ketika tebakan superpotensial diperoleh, nilai eigen dan fungsi eigen persamaan Schrodinger dapat diturunkan dengan mudah (Abu-Shady \& Ikot, 2019; Rasinariu, Mallow, \& Gangopadhyaya, 2007; Suparmi, Cari, \& Faniandari, 2020). Tidak hanya untuk menyelesaikan persamaan Schrodinger, metode ini juga digunakan untuk menyelesaikan persamaan golombang relativistik seperti persamaan Klein-Gordon (KGE) (Isonguyo, Okon, Ikot, \& Hassanabadi, 2014)(Yasuk, Durmus, \& Boztosun, 2006) dan persamaan Dirac (Hassanabadi, Maghsoodi, Zarrinkamar, \& Rahimov, 2011).

Penelitian ini bertujuan untuk mendapatkan solusi analitik berupa nilai eigen dan fungsi eigen dari persamaan Schrodinger dengan potensial Kratzer dalam sistem coordinat Bispherical menggunakan metode SUSY-QM. Pelitian ini perlu dilakukan karena belum ada penelitianpenelitian sebelumnya yang menganalisis persamaan Schrodinger terdeformasi- $q$ dengan 
potensial Kratzer dalam koordinat Bispherical. Penelitian ini terbagi menjadi dua bagian yakni untuk menentukan nilai eigen dan fungsi eigen persamaan Schrodinger dengan potensial Kratzer yang terdeformasi- $q$, dan nilai eigen dan fungsi eigen persamaan Schrodinger dengan potensial Kratzer yang tidak terdeformasi-q. Di Bab 2. Teori, kami memberika sedikit penjelasan tentang metode yang digunakan SUSY QM, sistem koordinat Bispherical dan persamaan Schrodinger terdeformasi- $q$. Bab 3. Hasil dan Pembahasan, kami menunjukan proses untuk mendapatkan solusi analitin persamaan Schrodinger masing-masing untuk persamaan Schrodinger dengan potensial Kratzer yang tidak terdeformasi- $q$ dan yang terdeformasi- $q$. Di bab terakhir, kami memberikan sedikit rangkuman dan komentar tentang penelitian ini.

\section{TEORI}

\subsection{Metode SUSY QM}

Suatu Hamiltonian $\mathrm{H}$ dapat difaktorkan menjadi gabungan dari pasangan super-Hamiltonian $H_{+}$dan $H_{-}$yang identik dan hanya berbeda pada nilai parameter-parameternya. Menggunakan sifat ini memungkinkan seseorang untuk menentukan tingkatan energi melalui proses iteratif (Gendenshteǐn \& Krive, 1985).

$$
H=\left(\begin{array}{cc}
H_{+} & 0 \\
0 & 0
\end{array}\right)+\left(\begin{array}{cc}
0 & 0 \\
0 & H_{-}
\end{array}\right)
$$

dengan

$$
H_{+}=-\frac{\hbar^{2}}{2 m} \frac{d^{2}}{d x^{2}}+U_{+}(x)=A^{-} A^{+} \quad ; \quad H_{-}=-\frac{\hbar^{2}}{2 m} \frac{d^{2}}{d x^{2}}+U_{-}(x)=A^{+} A^{-}
$$

Merupakan pasangan dari persamaan Hamiltonian satu dimensi, $U_{+}(x)$ dan $U_{-}(x)$ merupakan pasangan super-potensial

$$
U_{+}(x)=W^{2}(x)+\frac{\hbar}{\sqrt{2 m}} \frac{d W(x)}{d x} \quad ; \quad U_{-}(x)=W^{2}(x)-\frac{\hbar}{\sqrt{2 m}} \frac{d W(x)}{d x} \quad ;
$$

serta $A^{+}$dan $A^{-}$, masing-masing merupakan operator penaik dan operator penurun dalam suatu sistem SUSY mekanika kuantum.

$$
A^{+}=-\frac{\hbar}{\sqrt{2 m}} \frac{d}{d x}+W(x) \quad ; \quad A^{-}=+\frac{\hbar}{\sqrt{2 m}} \frac{d}{d x}+W(x) \quad ;
$$

Dikarenakan $H=H_{-}+E_{0}$, dengan demikian menggunakan persamaan (3-5), diperoleh hubungan antara super-potensial, energi dasar dan potensial efektif sebagai berikut

$$
U(x)=W^{2}\left(x ; a_{0}\right)-\frac{\hbar}{\sqrt{2 m}} \frac{d W}{d x}\left(x ; a_{0}\right)+E_{0}
$$

dimana $U(x)$ adalah potensial efektif sistem, dan $\mathrm{W}(x)$ adalah tebakan super-potensial yang ditentukan berdasarkan bentuk dari potensial efektif sistem terkait.

Fungsi dan nilai eigen dalam suatu sistem SUSY mekanika kuantum sejatinya sudah tersedia melalui pasangan super-Hamiltonian tetapi bukan spektrum yang sesungguhnya (Suparmi \& Cari, 2014). Dengan demikian dibutuhkan kondisi yang disebut shape invariance (Gendenshtein, 1984; Gendenshteĭn \& Krive, 1985). Secara matematis, kondisi ini dapat dituliskan menjadi

$$
U_{+}\left(x ; a_{j}\right)=U_{-}\left(x ; a_{j+1}\right)+\mathrm{R}\left(a_{j+1}\right)
$$

dengan $\mathrm{R}\left(a_{j+1}\right)$ adalah nilau residu yang bergantung pada fungsi $a$ saja, akan tetapi tidak pada $\mathrm{x}$, dan $a_{j+1}$ merupakan suatu fungsi dari $a_{j}$.

Hamiltonian $H_{-}$memiliki nilai eigen

$$
E_{n}^{(-)}=\sum_{j=1}^{n} R\left(a_{j}\right)
$$

dan total tingkatan energi 


$$
E_{n}=E_{0}+E_{n}^{(-)}
$$

Selanjutnya, persamaan operator penurun (7) dipakai untuk menentukan fungsi gelombang dasar dari sistem SUSY mekanika kuantum (Dutt, Gangopadhyaya, \& Sukhatme, 1997; Suparmi \& Cari, 2014),

$$
A^{-} \Psi_{0}^{(-)}=0
$$

\subsection{Koordinat Bispherical}

Persamaah Schrodinger dalam koordinat Bispherical bargantung pada $\mu, \theta$, and $\phi$. Selanjutnya, agar bisa menggunakan SUSY QM, persamaan Schrodinger perlu direduksi terlebih dahulu menjadi tiga persamaan yang masing-masingnya merupakan fungsi $\mu, \theta$, dan $\phi$. Hubungan antara koordinat Kartesian $(x, y, z)$ dan Bispherical $(\mu, \theta, \phi)$ adalah

$$
x=\frac{a \sin \theta \cos \phi}{\cosh \mu-\cos \theta} ; y=\frac{a \sin \theta \sin \phi}{\cosh \mu-\cos \theta} ; z=\frac{a \sinh \mu}{\cosh \mu-\cos \theta} \text {; }
$$

Dengan menggunakan hubungan,

$$
h_{i}^{2}=\left(\frac{\partial x}{\partial q_{i}}\right)^{2}+\left(\frac{\partial y}{\partial q_{i}}\right)^{2}+\left(\frac{\partial z}{\partial q_{i}}\right)^{2}
$$

diperoleh:

$$
h_{\mu}{ }^{2}=h_{\theta}{ }^{2}=\frac{a^{2}}{(\cosh \mu-\cos \theta)^{2}} \quad \text { dan } \quad h_{\phi}{ }^{2}=\frac{a^{2} \sin ^{2} \theta}{(\cosh \mu-\cos \theta)^{2}} \quad ;
$$

Dengan $h_{\mu}=h_{1}, h_{\theta}=h_{2}$, dan $h_{\phi}=h_{3}$. Selanjutnya, Laplacian dari koordinat Bispherical $\Psi(\mu, \theta, \phi)$ dapat diturunkan menjadi

$$
\begin{gathered}
\nabla_{B i s}^{2} \Psi=\frac{1}{h_{1} h_{2} h_{3}} \sum_{i=1}^{3} \frac{\partial}{\partial u^{i}}\left[\frac{h_{1} h_{2} h_{3}}{h_{i}{ }^{2}} \frac{\partial \Psi}{\partial u^{i}}\right]=\frac{(\cosh \mu-\cos \theta)^{3}}{a^{2} \sin \theta}\left\{\sin \theta \frac{\partial}{\partial \mu}\left[\frac{1}{\cosh \mu-\cos \theta} \frac{\partial \Psi}{\partial \mu}\right]+\right. \\
\left.\frac{\partial}{\partial \theta}\left[\frac{\sin \theta}{\cosh \mu-\cos \theta} \frac{\partial \Psi}{\partial \theta}\right]+\frac{1}{\sin \theta} \frac{\partial}{\partial \phi}\left[\frac{1}{\cosh \mu-\cos \theta} \frac{\partial \Psi}{\partial \phi}\right]\right\} \\
\text { Persamaan Schrodinger dalam koordinat Bispherical dapat ditulis menjadi } \\
\left(\nabla_{B i s}^{2}-\frac{2 m}{\hbar^{2}} U\right) \Psi=-\frac{2 m}{\hbar^{2}} E \Psi
\end{gathered}
$$

dengan $m$ adalah massa partikel yang bergerak pada permukaan koordinat Bispherical, dan $\hbar$ adalah konstanta Planck. Persamaan (15) dapat diselesaikan secara analitik, akan tetapi perlu dilakukan pemisahan variabel terlebih dahulu menggunakan suatu fungsi gelombang dengan bentuk (Morse \& Herman, 1953).

$$
\Psi=(\cosh \mu-\cos \theta)^{\frac{1}{2}} \Psi^{\prime}(\mu, \theta, \phi)
$$

Dengan melakukan substitusi persamaan (19) ke dalam (20), maka diperoleh

$$
\left(\nabla_{B i s}^{2}-\frac{2 m}{\hbar^{2}} U\right)(\cosh \mu-\cos \theta)^{\frac{1}{2}} \Psi^{\prime}=-\frac{2 m}{\hbar^{2}} E(\cosh \mu-\cos \theta)^{\frac{1}{2}} \Psi^{\prime}
$$

Persamaan (17) perlu direduksi menjadi tiga persamaan Schrodinger satu dimensi, masingmasing bergantung pada fungsi $\mu, \theta$, dan $\phi$. Dengan melakukan substitusi fungsi gelombang pada persamaan (16) kedalam (17), selanjutnya persamaan (17) ditulis kembali menjadi

$$
\frac{(\cosh \mu-\cos \theta)^{2}}{a^{2}}\left\{\frac{\partial^{2} \Psi^{\prime}}{\partial \mu^{2}}+\frac{\partial^{2} \Psi^{\prime}}{\partial \theta^{2}}+\cot \theta \frac{\partial \Psi^{\prime}}{\partial \theta}+\frac{1}{\sin ^{2} \theta} \frac{\partial^{2} \Psi^{\prime}}{\partial \phi^{2}}-\frac{1}{4} \Psi^{\prime}\right\}-\frac{2 m}{\hbar^{2}} U \Psi^{\prime}=-\frac{2 m}{\hbar^{2}} E \Psi^{\prime}
$$

Persamaan (18) dapat diselesaikan dengan menggunakan suatu variabel massa dengan bentuk

$$
m=\frac{m^{\prime} a^{2}}{(\cosh \mu-\cos \theta)^{2}}
$$

dimana $m^{\prime}$ merupakan suatu konstanta, dengan demikian persamaan (18) menjadi

$\left\{\frac{\partial^{2} \Psi^{\prime}}{\partial \mu^{2}}+\frac{\partial^{2} \Psi^{\prime}}{\partial \theta^{2}}+\cot \theta \frac{\partial \Psi^{\prime}}{\partial \theta}+\frac{1}{\sin ^{2} \theta} \frac{\partial^{2} \Psi^{\prime}}{\partial \phi^{2}}-\frac{1}{4} \Psi^{\prime}\right\}-\frac{2 m^{\prime}}{\hbar^{2}} U \Psi^{\prime}=-\frac{2 m \prime}{\hbar^{2}} E \Psi^{\prime}$

Dengan mengatur $\Psi^{\prime}=M(\mu) \Theta(\theta) \Phi(\phi)$ dan menggunakan bentuk potensial non-sentral 


$$
U=U(\mu)+U(\theta)+\frac{U(\phi)}{\sin ^{2} \theta}
$$

kedalam persamaan (20), maka persamaan tersebut tereduksi menjadi tiga buah persamaan Schrodinger satu dimensi sebagai beikut:

$$
\begin{aligned}
& \frac{\partial^{2} M(\mu)}{\partial \mu^{2}}-\frac{2 m^{\prime}}{\hbar^{2}} U(\mu) M(\mu)=\left(-\frac{2 m^{\prime}}{\hbar^{2}} E+\frac{1}{4}+\alpha_{2}\right) M(\mu) \\
& -\frac{1}{\sin \theta} \frac{\partial}{\partial \theta}\left(\sin \theta \frac{\partial \Theta(\theta)}{\partial \theta}\right)+\frac{2 m^{\prime}}{\hbar^{2}} U(\theta) \Theta+\frac{\alpha_{3}^{2} H}{\sin ^{2} \theta}=\alpha_{2} \Theta \\
& \frac{1}{\sin ^{2} \theta} \frac{\partial^{2} \Phi(\phi)}{\partial \phi^{2}}-\frac{2 m^{\prime}}{\hbar^{2}} U(\phi) \Phi(\phi)=-\alpha_{3} \Phi(\phi)
\end{aligned}
$$

dimana, $\alpha_{2}=b(b+1)$ dengan $b=0,1,2, \ldots$ adalah bilangan kuantum orbital, dan $\alpha_{3}=k^{2}$ dengan $k=0, \pm 1, \pm 2, \ldots$ merupakan bilangan kuantum magnetik ketika $U(\theta)=U(\phi)=0$.

\subsection{Deformasi Mekanika Kuantum}

Hubungan komutatif antara posisi dan momentum didefinisikan kedalam bentuk (Sobhani, Chung, \& Hassanabadi, 2017)

$$
[\widehat{x}, \hat{p}]=i \hbar\left(1+q \mu^{2}\right) ; \quad \widehat{x}, \leftrightarrow \mu: \widehat{p},=-i \hbar D_{\mu}
$$

dengan

$$
\widehat{p},=-i \hbar D_{\mu}^{q}=-i \hbar\left(1+q \mu^{2}\right) \frac{\partial}{\partial \mu}
$$

Bentuk kuadrat dari deformasi- $q$ pada persamaan (26) adalah

$$
D_{\mu}^{q^{2}}=\left(1+q \mu^{2}\right)^{2} \frac{\partial^{2}}{\partial \mu^{2}}+2 q \mu\left(1+q \mu^{2}\right) \frac{\partial}{\partial \mu}
$$

Melakukan pergantian $\frac{\partial^{2}}{\partial \mu^{2}} \rightarrow D_{\mu}^{q^{2}}$ dengan cara substitusi persamaan (27) into (22) diperoleh persamaan Schrodinger yang terdeformasi sebagai berikut

$$
\left(1+q \mu^{2}\right)^{2} \frac{\partial^{2} M(\mu)}{\partial \mu^{2}}+2 q \mu\left(1+q \mu^{2}\right) \frac{\partial M(\mu)}{\partial \mu}-\frac{2 m^{\prime}}{\hbar^{2}} U(\mu) M(\mu)=\left(-\frac{2 m^{\prime}}{\hbar^{2}} E_{q B}+\alpha_{2}+\frac{1}{4}\right) M(\mu)
$$

Persamaan (28) dapat diselesaikan secara analitik apabila mengenalkan suatu parameter baru (Suparmi, Dianawati, \& Cari, 2020)

$$
s=\mu \sqrt{q} \rightarrow d s=\sqrt{q} d \mu \rightarrow d \mu=\frac{d s}{\sqrt{q}}
$$

Dengan menulis kembali persamaan (27) mejadi

$$
D_{s}^{q^{2}}=q\left(1+s^{2}\right)^{2} \frac{d^{2}}{d s^{2}}+2 q\left(1+s^{2}\right) \frac{d}{d s}
$$

maka, persamaan Schrodinger dengan fungsi $\mu$ (31) tereduksi menjadi persamaan Schrodinger terdeformasi- $q$ yang bergantung pada fungsi $s$

$$
\begin{aligned}
& q\left(1+s^{2}\right)^{2} \frac{d^{2}}{d s^{2}} M(s)+2 q s\left(1+s^{2}\right) \frac{d}{d s} M(s)+\frac{2 m^{\prime}}{\hbar^{2}} 2 D_{e}\left(\sqrt{q} \frac{r_{0}}{s}-\frac{1}{2} \frac{q r_{0}}{s^{2}}\right) M(s)= \\
& \left(-\frac{2 m^{\prime}}{\hbar^{2}} E_{q B}+\alpha_{2}+\frac{1}{4}\right) M(s)
\end{aligned}
$$

Kita dapat mengaplikasikan potensial Kratzer (1) kedalam persamaan (31) dengan bentuk,

$$
U(\mu)=U(s)=q \frac{D_{e} r_{0}}{s^{2}}-\sqrt{q} \frac{2 D_{e} r_{0}}{s}
$$

\section{HASIL DAN PEMBAHASAN}

\subsection{Solusi persamaan Schrodinger tanpa deformasi-q}

Dalam subbab ini, proses penyelesaian persamaan Schrodinger yang dipengaruhi potensial Kratzer dalam koordinat Bispherical dengan mengabaikan deformasi- $q$ diturunkan dengan 
baik. Dimulai dengan mamasukan persamaan potensial Kratzer (1) kedalam persamaan Schrodinger (22)

$$
-\frac{\hbar^{2}}{2 m^{\prime}} \frac{\partial^{2} M(\mu)}{\partial \mu^{2}}+\frac{\hbar^{2}}{2 m^{\prime}}\left(\frac{v(v+1)}{\mu^{2}}-\frac{2 \gamma}{\mu}\right) M(\mu)=E^{\prime} M(\mu)
$$

dengan

$$
v=-\frac{1}{2}-\sqrt{\frac{2 m^{\prime}}{\hbar^{2}} D_{e} r_{0}+\frac{1}{4}}(34) ; \gamma=\frac{2 m^{\prime}}{\hbar^{2}} D_{e} r_{0} \quad(35) ; \quad E^{\prime}=E_{B}-\frac{\hbar^{2}}{2 m^{\prime}}\left(\alpha_{2}+\frac{1}{4}\right)
$$

dan potensial efektif untuk persamaan (33) adalah

$$
U_{\text {eff }}(\mu)=\frac{\hbar^{2}}{2 m}\left(\frac{v(v+1)}{\mu^{2}}-\frac{2 \gamma}{\mu}\right)
$$

Tebakan super-potensial yang sesuai dengan potensial efektif (37) adalah

$$
W(\mu)=\frac{\hbar}{\sqrt{2 m}}\left(\frac{V}{\mu}-\frac{G}{V}\right)
$$

Dengan melakukan substitusi persamaan (38) kedalam (6) maka diperoleh

$$
\frac{\hbar^{2}}{2 m}\left(\frac{v(v+1)}{\mu^{2}}-\frac{2 \gamma}{\mu}\right)-E_{0}=\frac{\hbar^{2}}{2 m}\left(\frac{V(V+1)}{\mu^{2}}-\frac{2 G}{\mu}\right)+\frac{\hbar^{2}}{2 m}\left(\frac{V(V+1)}{\mu^{2}}-\frac{2 G}{\mu}\right)+\frac{\hbar^{2}}{2 m} \frac{G^{2}}{V^{2}}
$$

Dari persamaan (39) diperoleh beberapa hubungan antar variabel sebagai berikut: $V=v, G=$ $\gamma$, dan $E_{0}=-\frac{G^{2}}{V^{2}}$. Dengan menggunakan hubungan ini, selanjutnya persamaan tebakan superpotensial (38) dapat ditulis kembali menjadi super-potensial

$$
W(\mu)=\frac{\hbar}{\sqrt{2 m}}\left(\frac{v}{\mu}-\frac{\gamma}{v}\right)
$$

Pasangan super-potensial $U_{-}\left(\mu ; a_{0}\right)$ dan $U_{+}\left(\mu ; a_{0}\right)$ dapat dengan mudah diperoleh dengan mensubtitusikan persamaan (40) kedalam persamaan (4).

$$
U_{-}\left(\mu ; a_{0}\right)=\frac{\hbar^{2}}{2 m}\left(\frac{v(v+1)}{\mu^{2}}-\frac{2 \gamma}{\mu}\right)+\frac{\hbar^{2}}{2 m} \frac{\gamma^{2}}{v^{2}}(41) ; U_{+}\left(\mu ; a_{0}\right)=\frac{\hbar^{2}}{2 m}\left(\frac{v(v-1)}{\mu^{2}}-\frac{2 \gamma}{\mu}\right)+\frac{\hbar^{2}}{2 m} \frac{\gamma^{2}}{v^{2}}
$$

Selanjutnya, dengan mengatur $v \rightarrow v-1$ pada persamaan (61) dan (62) scara berurutan, bntuk dari super-potensial slanjutnyal $U_{\mp}\left(\mu ; a_{1}\right), U_{\mp}\left(\mu ; a_{2}\right)$ dapat diturunkan. Kemudian, dengan menggunakan pasangan-pasangan super-potensial ini pada persamaan shape invariance (9) maka diperoleh persamaan residu

$$
R\left(a_{n}\right)=U_{+}\left(\mu ; a_{n-1}\right)-U_{-}\left(\mu ; a_{n}\right)=\frac{\hbar^{2}}{2 m} \frac{\gamma^{2}}{(v-1-n)^{2}}-\frac{\hbar^{2}}{2 m} \frac{\gamma^{2}}{(v-n)^{2}}
$$

Dengan mensubstitusikan persamaan (45) kedalam persamaan (8), kemudian menggunakan persamaan (9), diperoleh nilai eigen untuk persamaan (33) sebagai berikut

$$
E^{\prime}=-\frac{\hbar^{2}}{2 m} \frac{\gamma^{2}}{v^{2}}+\frac{\hbar^{2}}{2 m} \frac{\gamma^{2}}{v^{2}}-\frac{\hbar^{2}}{2 m} \frac{\gamma^{2}}{(v-n)^{2}}=-\frac{\hbar^{2}}{2 m} \frac{\gamma^{2}}{(v-n)^{2}}
$$

Dengan merujuk pada persamaan (36) maka energi dari persamaan Schrodinger dengan potensial Kratzer dalam koordinat Bispherical adalah sebagai berikut.

$$
E_{B}=-\frac{\hbar^{2}}{2 m} \frac{\left(\frac{2 m^{\prime}}{\hbar^{2}} D_{e} r_{0}\right)^{2}}{\left(-\frac{1}{2}-\sqrt{\left(\frac{2 m^{\prime}}{\hbar^{2}}\right) D_{e} r_{0}+\frac{1}{4}}-n\right)^{2}}+\frac{\hbar^{2}}{2 m^{\prime}}\left(b(b+1)+\frac{1}{4}\right)
$$

Operator pembangkit dan penurun untuk persamaan Schrodinger dengan potensial Kratzer dalam koordinat Bispherical dapat dengan mudah ditentukan dengan melakukan substitusi persamaan super-potensial (40) kedalam persamaan (5).

$$
A^{ \pm}(\mu)=\mp \frac{\hbar}{\sqrt{2 m}} \frac{d}{d r}+\frac{\hbar}{\sqrt{2 m}}\left(\frac{v}{\mu}-\frac{\gamma}{v}\right)
$$

Dengan demikian, menggunakan operator penurun dan persanaam (10) maka fungsi gelombang dasar untuk sistem ini adalah 


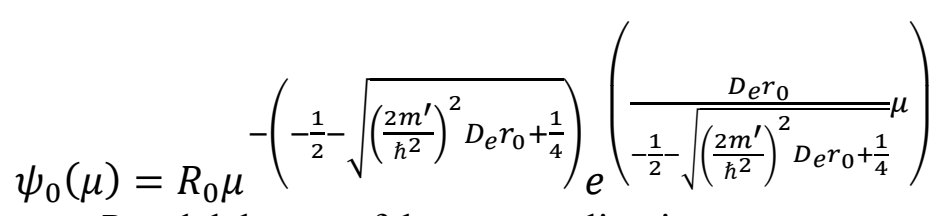

dengan $R_{0}$ adalah suatu faktor normalisasi.

\subsection{Solusi persamaan Schrodinger terdeformasi-q}

Persamaan Schrodinger terdeformasi-q (31) tidak dapat diselesaikan secara langsung menggunakan metode SUSY QM karena persamaan tersebut memiliki bentuk turunan pertama dan kedua. Oleh karena itu, persamaan tersebut perlu direduksi terlebih dahulu menjadi persamaan yang hanya memiliki bentuk turunan kedua. Untuk itu, kita perlu mengatur

$$
s=\cot s^{\prime} \rightarrow d s=-c s c^{2} s^{\prime} d s^{\prime} ; 1+s^{2}=1+\cot ^{2} s^{\prime}=c s c^{2} s^{\prime}
$$

sehingga,

$$
\frac{d s^{\prime}}{d s}=-\frac{d}{d s^{\prime}} \frac{1}{c s c^{2} s^{\prime}}
$$

kemudian, suku pertama pada persamaan (31) dapat dituliskan menjadi

$$
\frac{d^{2}}{d s^{\prime 2}}=\frac{1}{c s c^{4} s^{\prime}} \frac{d^{2}}{d s^{\prime 2}}-\frac{2 c o t s^{\prime}}{c s c^{4} s^{\prime}} \frac{d}{d s^{\prime}}
$$

Dengan demikian, persamaan Shrodinger terdeformasi- $q$ dapat ditulis mejadi

$$
\begin{aligned}
& -\frac{\hbar^{2}}{2 m^{\prime}} \frac{d^{2}}{d s^{\prime 2}} M\left(s^{\prime}\right)+\frac{\hbar^{2}}{2 m^{\prime}}\left(\frac{\varrho(\varrho+1)}{\cos ^{2} s^{\prime}}\right. \\
& \text { dimana } \\
& \varrho=-\frac{1}{2}-\sqrt{\frac{2 m^{\prime}}{\hbar^{2}} D_{e} r_{0}+\frac{1}{4}} \\
& S=\frac{2 m^{\prime}}{\hbar^{2}} \frac{D_{e} r_{0}}{\sqrt{q}} \\
& E^{\prime}=\left(\frac{E_{q B}}{q}+D_{e} r_{0}\right)-\frac{\hbar^{2}}{2 m^{\prime}} \frac{\alpha_{2}+\frac{1}{4}}{q}
\end{aligned}
$$

Persamaan (53) dapat dengan mudah diselesaikan secara analitik menggunakn metode SUSY dengan mengatur tebakan super-potensial sebagai berikut.

$$
W\left(s^{\prime}\right)=\frac{\hbar}{\sqrt{2 m^{\prime}}}\left(\text { Htans }^{\prime}-\frac{G}{H}\right)
$$

Dengan mengaplikasikan potensial efektif dari persamaan (53) dan tebakan super-potensial (57) kedalam persamaan (6), kita peroleh beberapa hubungan parameter $H=-\varrho, G=\varsigma$, and $E_{0}=-\frac{\hbar^{2}}{2 m^{\prime}}\left(\frac{\varsigma^{2}}{\varrho^{2}}-\varrho^{2}\right)$. Dengan demikian, tebakan super-potensial (57) dapat ditulis kembali menjadi super-potensial sebagai berikut.

$$
W\left(s^{\prime}\right)=\frac{\hbar}{\sqrt{2 m^{\prime}}}\left(-\varrho \operatorname{tans}^{\prime}+\frac{\varsigma}{\varrho}\right)
$$

Dengan menggunakan proses-proses yang sama seperti pada persamaan (42) - (46) dan (48) maka diperoleh energi

$$
\begin{gathered}
E_{q B}=\left[-\frac{\hbar^{2}}{2 m^{\prime}}\left(\frac{\left(\frac{2 m^{\prime} D_{e} r_{0}}{\hbar^{2} \sqrt{q}}\right)^{2}}{\left(-\frac{1}{2}-\sqrt{\frac{2 m^{\prime}}{\hbar^{2}} D_{e} r_{0}+\frac{1}{4}}-n\right)^{2}}-\left(-\frac{1}{2}-\sqrt{\frac{2 m^{\prime}}{\hbar^{2}} D_{e} r_{0}+\frac{1}{4}}-n\right)^{2}\right)-D_{e} r_{0}\right] q+ \\
\frac{\hbar^{2}}{2 m^{\prime}}\left(b(b+1)+\frac{1}{4}\right)
\end{gathered}
$$

dan fungsi gelombang dasar untuk sistem persamaan Schrodinger terdeformasi- $q$ dengan potensial Kratzer dalam koordinat Bispherical dapat diperoleh sebagai berikut 


$$
\begin{aligned}
& \psi_{0}(\mu)=R_{q 0}\left(\operatorname{secs}^{\prime}\right)\left(-\frac{1}{2}-\sqrt{\frac{2 m \prime}{\hbar^{2}} D_{e} r_{0}+\frac{1}{4}}\right) e^{-\frac{\frac{2 m^{\prime} D_{e} r_{0}}{\hbar^{2} \sqrt{q}}}{\left(-\frac{1}{2}-\sqrt{\frac{2 m \prime}{\hbar^{2}} D_{e} r_{0}+\frac{1}{4}}\right)}} \\
& \text { dengan } R_{q 0} \text { adalah suatu faktor normalisasi. }
\end{aligned}
$$

\section{KESIMPULAN}

Dalam penelitian ini, nilai eigen dan fungsi eigen dari persamaan Schrodinger yang dipengaruhi potensial Kratzer dalam koordinat Bispherical $(\mu, \theta, \phi)$ yang terdeformasi- $q$ dan tidak terdeformasi- $q$ berhasil diturunkan dengan jelas dan sistematis. Persamaan Schrodinger yang bergantung posisi $(\mu, \theta, \phi)$ menggunakan metode pemisahan variabel dan menghasilkan tiga persamaan Schrodinger satu dimensi, masing-masing sebagai fungsi $\mu, \theta$, dan $\phi$. Persamaan Schrodinger yang bergantung $\mu$ dan tidak terdeformasi- $q$ dengan potensial Kratzer diselesaikan menggunakan metode SUSY QM. Menggunakan pemisalah parameter yang tepat, persamaan Schrodinger yang bergantung $\mu$ dan terdeformasi- $q$ tereduksi menjadi persamaan Schrodinger dengan fungsi $s^{\prime}$ dan bisa diselesaikan menggunakan metode SUSY QM. Berdasarkan persamaan energi untuk sistem terdeformasi- $q$ dapat diketahui bahwa, jika nilai parameter- $q$ diatur sama dengan nol maka persamaan tersebut tereduksi menjadi persamaan persamaan energi untuk sistem tanpa deformasi- $q$.

\section{ACKNOWLEDGEMENT}

Penelitian ini disupport oleh Mandatory Research Grant of Sebelas Maret University with contract number 452/UN27.21/PN/2020.

\section{DAFTAR PUSTAKA}

Abu-Shady, M., \& Ikot, A. N. (2019). Analytic solution of multi-dimensional Schrödinger equation in hot and dense QCD media using the SUSYQM method. European Physical Journal Plus, 134(7).

Alvarez-Cas, Tillo, D. E., \& Kirchbach, M. (2007). Exact spectrum and wave functions of the hyperbolic Scarf potential in terms of finite Romanovski polynomials. Revista Mexicana De Fisica, 53(2), 143-154.

Anthonys, G. (2018). Analytical solutions for two ferromagnetic nanoparticles immersed in a magnetic field: Mathematical model in bispherical coordinates. In Synthesis Lectures on Electrical Engineering.

Atre, R., Kumar, A., Kumar, N., \& Panigrahi, P. K. (2004). Quantum-information entropies of the eigenstates and the coherent state of the Poschl-Teller potential. PHYSICAL REVIEW A, 65(5), 1-6.

Awoga, O. A., \& Ikot, A. N. (2012). Approximate solution of Schrodinger equation in D dimensions for inverted generalized hyperbolic potential. Pramana - Journal of Physics, 79(3), 345-356.

Belov, V. V., Dobrokhotov, S. Y., \& Tudorovskii, T. Y. (2004). Asymptotic solutions of nonrelativistic equations of quantum mechanics in curved nanotubes: I. Reduction to spatially one-dimensional equations. Theoretical and Mathematical Physics, 141(2), $1562-1592$.

Berkdemir, C., Berkdemir, A., \& Han, J. (2006). Bound state solutions of the Schrodinger 
equation for modified Kratzer's molecular potential. Chemical Physics Letters, 417(46), 326-329.

Cheng, Y. F., \& Dai, T. Q. (2007). Exact Solution Of The Schrödinger Equation For The Modified Kratzer potential Plus A Ring-Shaped Potential By The Nikiforov-Uvarov Method. Physica Scripta, 75(3), 274-277.

Durmus, A., \& Yasuk, F. (2007). Relativistic and nonrelativistic solutions for diatomic molecules in the presence of double ring-shaped Kratzer potential. Journal of Chemical Physics, 126(7).

Dutt, R., Gangopadhyaya, A., \& Sukhatme, U. P. (1997). Noncentral potentials and spherical harmonics using supersymmetry and shape invariance. American Journal of Physics, 65(5), 400-403.

Ebomwonyi, O., Onate, C. A., Onyeaju, M. C., \& Ikot, A. N. (2017). Any 1-states solutions of the Schrödinger equation interacting with Hellmann-generalized Morse potential model. Karbala International Journal of Modern Science, 3(1), 59-68.

Encinosa, M., \& Etemadi, B. (2002). Power series Schrodinger eigenfunctions for a particle on the torus. 32307. Retrieved from http://arxiv.org/abs/quant-ph/0205001

Faniandari, S., Suparmi, A., \& Cari, C. (2020). Analytical Solution of Schrodinger Equation For Yukawa Potential with Variable Mass in Toroidal Coordinate Using Supersymmetric Quantum Mechanics. Periodico Tche Quimica, 17, 100-108.

Ferrari, G., \& Cuoghi, G. (2008). Schrödinger equation for a particle on a curved surface in an electric and magnetic field. Physical Review Letters, 100(23), 1-4.

Gendenshtein, L. E. (1984). by equation of the Schr0dinger of exact spectra Derivation of supersymmetry means. Pis'ma Zh. Eksp. Teor. Fiz., 38(6), 356-359.

Gendenshteĭn, L., \& Krive, I. V. (1985). Supersymmetry in quantum mechanics. Soviet Physics - Uspekhi, 28(8), 645-666.

Hassanabadi, H., Ikot, A. N., \& Zarrinkamar, S. (2014). Exact solution of Klein-Gordon with the Pöschl-Teller Double-Ring-Shaped Coulomb Potential. Acta Physica Polonica A, 126(3), 647-651.

Hassanabadi, H., Maghsoodi, E., Zarrinkamar, S., \& Rahimov, H. (2011). An approximate solution of the Dirac equation for hyperbolic scalar and vector potentials and a Coulomb tensor interaction by susyqm. Mod. Phys. Lett. A, 26(36), 2703-2718.

Ikhdair, S. M., \& Sever, R. (2007). Exact solutions of the radial Schrödinger equation for some physical potentials. Central European Journal of Physics, 5(4), 516-527.

Ikot, A. N., Okorie, U., Ngiagian, A. T., Onate, C. A., Edet, C. O., Akpan, I. O., \& Amadi, P. O. (2020). Bound state solutions of the Schrödinger equation with energy-dependent molecular Kratzer potential via asymptotic iteration method. Eclética Química Journal, 45(1), 65-76.

Isonguyo, C., Okon, I. B., Ikot, A. N., \& Hassanabadi, H. (2014). Solution of Klein Gordon Equation for Some Diatomic Molecules with New Generalized Morse-like Potential Using SUSYQM Solution of Klein Gordon Equation for Some Diatomic Molecules with New Generalized Morse-like Potential Using SUSYQM. Korean Chem. Soec., $35(12)$. 
Karayer, H. H. (2019). Analytical solution of D-dimensional radial Schrödinger equation for sextic potential by the extended Nikiforov-Uvarov method and biconfluent Heun polynomials. Turkish Journal of Physics, 43(4), 410-416.

Kocak, G., Bayrak, O., \& Boztosun, I. (2012). Supersymmetric solution of Schrödinger equation by using the asymptotic iteration method. Annalen Der Physik, 524(6-7), 353-359.

Krejčiřík, D., \& Raymond, N. (2014). Magnetic Effects in Curved Quantum Waveguides. Annales Henri Poincare, 15(10), 1993-2024.

Mir-Kasimov, R. M. (2013). Factorization method for Schrödinger equation in relativistic configuration space and q-deformations. Physics of Particles and Nuclei, 44(3), 422436.

Moon, P., \& Spencer, D. E. (1971). Field Theory Handbook: Including Coordinate Systems, Differential Equations and Their Solutions (3rd ed.).

Morse, P. M., \& Herman, F. (1953). Methods Of Theoretical Physics. New York: McGrawHill.

Rasinariu, C., Mallow, J. V., \& Gangopadhyaya, A. (2007). Exactly solvable problems of quantum mechanics and their spectrum generating algebras: A review. Central European Journal of Physics, 5(2), 111-134.

Shishan, D., Dong, S., Bahlouli, H., \& Bezerra, V. B. (2011). Algebraic Approach To The Klein Gordon Equation With Hyperbolic Scarf Potential. 20(1), 55-61.

Sobhani, H., Chung, W. S., \& Hassanabadi, H. (2017). Investigation of spin-zero bosons in qdeformed relativistic quantum mechanics. Indian Journal of Physics, 92(4), 529-536.

Suparmi, A., Cari, C., \& Faniandari, S. (2020). Eigen solutions of the Schrodinger equation with variable mass under the influence of the linear combination of modified WoodsSaxon and Eckart potentials in toroidal coordinate. Molecular Physics.

Suparmi, A., Dianawati, D. A., \& Cari, C. (2020). Hypergeometric method for Klein-Gordon equation with q-deformed quantum mechanics on coulomb potential. Journal of Physics: Conference Series, 1511(1).

Suparmi, \& Cari. (2014). Bound state solution of dirac equation for generalized pöSchl-Teller plus trigomometric Pöschl-Teller Non-Central potential using SUSY quantum mechanics. Journal of Mathematical and Fundamental Sciences, 46(3), 205-223.

Taskin, F., \& Kocakt, G. (2010). Approximate solutions of Schrodinger equation for Eckart potential with centrifugal term. Chinese Physics B, 19(9), 1-6.

Yasuk, F., Durmus, A., \& Boztosun, I. (2006). Exact analytical solution to the relativistic KleinGordon equation with noncentral equal scalar and vector potentials. Journal of Mathematical Physics, 47(8).

Zhang, Y., Liang, H. Z., \& Meng, J. (2009). Solving the dirac equation with nonlocal potential by imaginary time step method. Chinese Physics Letters, 26(9), 2007-2010. 